\title{
Association between maternal lifestyle and preschool nutrition
}

\author{
Érica Bezerra Nobre ${ }^{1 *}$, Alexandra Valéria Maria Brentani ${ }^{2}$, Alexandre Archanjo Ferraro ${ }^{3}$ \\ ${ }^{1}$ MSc. Nutritionist, University Restaurant, Fundação Universidade de Brasília (FUB), Brasília, Distrito Federal, Brazil \\ ${ }^{2}$ Postdoc. PhD Professor, Department of Pediatrics, Faculdade de Medicina, Universidade de São Paulo (FMUSP), São Paulo, SP, Brazil \\ ${ }^{3}$ Postdoc. PhD Professor, Department of Pediatrics, FMUSP, São Paulo, SP, Brazil
}

\section{SUMMARY}

Introduction: Many of the health behaviors involved in the emergence of chronic non-communicable diseases (CNCD) are originated in childhood under parental influence. Mothers are the ones most involved in the education and health care of children. Lifestyle (LS) is a social determinant of health. Very few studies tried to understand the influence of maternal LS on child nutrition.

Objective: To verify the association between maternal behavioral and non-behavioral LS and nutritional aspects in preschool children.

Method: From January 2010 to December 2010, we performed a cross-sectional study with 255 mothers of preschool children who were residents of five different sub-districts in southwestern São Paulo. A proportional stratified random sample was selected using two layers ("schools" and "children"). From the mother, sociodemographic and LS information were collected. From the child, data on anthropometry, sedentary behavior and food intake were collected. The association was calculated using chi-square test and logistic regression.

Study conducted in the southwest

of São Paulo's greater area and

conducted by researchers from the

Department of Pediatrics, Faculdade de Medicina, Universidade de São Paulo

(FMUSP), São Paulo, SP, Brazil

Article received: 6/29/2016 Accepted for publication: 7/26/2016

*Correspondence: Departamento de Pediatria Address: Av. Dr. Enéas de Carvalho Aguiar, 647

São Paulo, SP - Brazil Postal code: 05403-000 ericanobre@usp.br

Results: Children who ate minimally processed food were born from mothers with more socially aware non-behavioral LS, while children that ate more processed food were born from mothers with more consumerist non-behavioral LS. No association was found between nutritional characteristics of preschoolers and types of maternal behavioral LS. Children presenting "sedentary behavior" and the habit of eating "ultra-processed foods" had $113 \%$ and $84 \%$ higher chances, respectively, of being born to mothers that belonged to the "consumerist" cluster.

Conclusion: Mothers living a consumerist lifestyle can promote negative influences on child nutrition.

Keywords: mother-child relations, lifestyle, preschool child, nutritional status, motor activity, child nutrition.

INTRODUCTION

Diseases associated with behavior and lifestyle (LS) are gaining great attention in all age groups, especially pediatric, since chronic non-communicable diseases (CNCD) have their onset in childhood. The epidemiological transition that occurred in several countries with reduction of infectious diseases and increase in CNCDs drove the health sector to conduct research to understand the health behaviors involved in this increase, especially concerning the mother-child relationship. ${ }^{1}$

Research studying the relationship between mothers and children mainly investigate parenting practices in re-

lation to food and sedentary behavior of the child; ${ }^{2-6}$ parental perception of the child's weight; ${ }^{7-12}$ use of food as a tool for the establishment of maternal and child emotional relationship; ${ }^{13-15}$ study of parental behavioral LS and the child's nutritional status and physical activity; ${ }^{16-25}$ relationship of maternal depression on children's nutritional status; ${ }^{26-30}$ and, last, clinical studies on the development process of CNCD with onset in childhood. ${ }^{31-34}$ None of these study the mother-child relationship. Thus, it is possible to understand that few studies have been conducted with regard to the influence of maternal LS on child health.
\end{abstract}


Parental LS, especially the mother's, is associated with children's health because it affects the environment in which the child grows and develops. The LS approach is not limited to health behaviors but includes non-behavioral characteristics, such as personal values, family life, and social life. Given that children are subject to the influence of the environment and of people, especially their mother's, the figure most involved in their care, it is important to assess how the two approaches of LS - behavioral and non-behavioral - are associated with nutritional aspects of preschoolers.

There is a lack of studies on maternal LS including the two approaches and their association with nutritional aspects of the child. A wider knowledge of this issue may contribute with information for the prevention and control of health problems and diseases resulting from the mother-child relationship. This study aims to verify the association between maternal LS and nutritional aspects of preschoolers.

\section{Method}

\section{Study design}

From January to December 2010, a cross-sectional study was conducted with mothers of preschool children, aged 3 to 5 years, residents of the subdistricts of Butantã, Morumbi, Raposo Tavares, Rio Pequeno, and Vila Sônia in southwest São Paulo, state of São Paulo. Research protocol number 1385/09 was approved by the Ethics Committee for Research Project Analysis of the Department of Internal Medicine, Hospital das Clínicas, Faculdade de Medicina, Universidade de São Paulo.

\section{Sampling}

The target population comprised all mothers of preschool children and the preschool children from the district of Saúde do Butantã, Greater São Paulo area. The sample unit was the mother-child dyad.

Sample size was calculated based on $\alpha=0.05$ and $\beta=0.20$, with minimum factor load of 0.35 both for the non-behavioral lifestyle questionnaire and the food frequency questionnaire, requiring 250 (two hundred and fifty) mother-child pairs for association with the outcome (and "standard error considered as double those of conventional coefficients"). ${ }^{35}$ Information on 255 motherchild dyads was collected.

A proportional stratified random sample was selected using two layers ("schools" and "children"). The sampling grid was the full list of public and private preschools registered with the Regional Board of Education of subdistrict of Saúde do Butantã, in southwest São Paulo. The number of schools required to perform the sampling was not proportional to the number of schools per region, since the total number of schools (public and private) required, proportional to the existing, would be less than three. However, we decided to choose three schools of each type by region.

The inclusion criterion was that the children were properly enrolled and regularly attending classes in the first or second levels of preschool. Children with neurological impairment were excluded. One child was excluded from the study.

In the case of public schools, it was necessary to obtain a research permit with the regional education director. After authorization, all schools (public and private) registered with the Regional Board of Education were listed by region and selected by draw. A contact with the director of the school drawn was made to obtain research consent. Then, all children aged 3 to 5 years of each school were listed and selected by draw. Notes with information about the research were placed on the selected children's diary, directed to their mothers. Those who agreed to participate gave their name and phone number and a contact was made by the fieldworker trained for the activities, who would then go to the child's home or school to conduct the interview. Before starting it, the mother read and, if she agreed to participate, signed a Term of Free and Informed Consent. The interview was conducted at home or in the school environment without influence of others.

\section{Variables collected and instruments}

Data collection was done by students of nutrition from the sixth semester, who had been trained for this purpose.

In relation to the child's mother, the following data were collected:

1. Age in years.

2. Economic status: evaluated according to the 2009 Economic Classification Criteria of Brazil. ${ }^{36}$ The assessment was made based on a point system divided into five categories related to the number of goods that the family had at home. We chose to group classes A1 and A2 as class A only, and so on until we ended up with five classes: A, B, C, D and E.

3. Maternal education: We also analyzed education according to the Economic Classification Criteria of Brazil, ${ }^{36}$ dividing it into five categories: illiterate, complete primary school, complete middle school, complete high school, and university graduates.

4. Marital status: Divided into five categories, including single, married, separated, divorced, or widowed.

5. Lifestyle: Assessed according to two instruments, behavioral ${ }^{37}$ and non-behavioral. ${ }^{1}$ 
The "FANTASTIC" epidemiological LS questionnaire measures health behaviors. The acronym "FANTASTIC" refers to each area analyzed. In all, there are 25 items divided into nine domains. Each letter addresses a specific subject, as follows:

- "F" for "Family" and "Friends";

- "A" for "Activity" (physical activity);

- "N" for "Nutrition";

- "T" for "Tobacco" and "Toxics" (tobacco and drugs);

- "A" for "Alcohol";

- "S" for "Sleep", "Seatbelts", "Stress", "Safe Sex";

- "T" for "Type of behavior";

- "I" for "Insight"; and

- "C" for "Career" (work, satisfaction with the profession). ${ }^{38}$

For 23 items, the answers are arranged as a Likert scale. For two items, the answers are dichotomous. The sum of all points ranked the individual's behavioral lifestyle into one of five categories: "Excellent" (85-100 points); "Very good" (70-84 points); "Good" (55-69 points); "Regular" (35-54 points); and "Needs improvement" (0-34 points) ${ }^{37}$ The other questionnaire, sociological or non-behavioral, measures the activities, interests, opinions and values of mothers towards life. ${ }^{1}$ In all, there are 53 items divided into two sections. The first section contains 24 items about the mother's personal values, while the second section contains 29 items related to their activities, interests and opinions.

As for the children, the following information was collected:

1. Age in years.

2. Anthropometric data: Weight, height, and waist circumference were measured. Weight was measured using a Plenna Wind ${ }^{\circledast}$ digital scale, with 100 g-precision and maximum capacity of $150 \mathrm{~kg}$, calibrated on a flat, smooth, and hard surface. The child's height was measured in meters using a portable Wood Compact Stadiometer WCS, coupled to a non-extensible tape with a $0-220 \mathrm{~cm}$ range and accuracy within 1 $\mathrm{mm}$. Waist circumference was measured using a non-stretchable Corrente ${ }^{\circledR}$ tape measure with a range of $150 \mathrm{~cm}$ and accuracy within $1 \mathrm{~mm}$. Measurements of weight, height, and waist circumference were obtained according to criteria established by the Ministry of Health ${ }^{39}$ and the cutoff points used for waist circumference were those established by Taylor et al., ${ }^{40}$ according to age.

3. Nutritional status: Assessed based on weight and height. Data for weight and height measurements, date of birth, and questionnaire assessments were transferred into WHO Anthro ${ }^{41}$ software - for children up to the age of 5 - and WHO AnthroPlus ${ }^{42}$ software - for children over the age of 5; z-scores for BMI/age were then calculated. The classification of nutritional status for children from 0 to 5 years old and above 5 years old followed the criteria established by the Ministry of Health $^{39}$ and the BMI index for age was used.

4. Sedentary behavior: Verified based on a question about how many minutes the child would spend watching television, including video games, movies, cartoons etc. The cutoff point for sedentary behavior was the mark of more than 120 minutes per day in front of the television. ${ }^{43}$

5. Food intake: Characterized on the basis of a Food Frequency Questionnaire (FFQ) specific to the age group under study. ${ }^{44}$ This questionnaire assesses the frequency of dietary intake of 56 items divided into nine food groups. The answers to frequency of each item intake were: never, less than once a month, once to three times per month, once per week, 2 to 4 times a week, once a day, twice or more times per day.

\section{Statistical analyses}

Factor and cluster analysis in the maternal non-behavioral lifestyle questionnaire

First, a factor analysis was conducted on the non-behavioral lifestyle questionnaire comprising 53 items. ${ }^{1}$ The Bartlett's sphericity test produced a p-value $<0.001$ and the Kaiser Mayer Olkin test, a value of 0.83 , indicating that the correlation matrix was suitable for factor analysis. The latter generated five factors with eigenvalues greater than 1.5. The scree plot identified five factors previous to the inflection point of the curve, which were retained and orthogonally rotated. They explained $79 \%$ of the total variance. After rotation, each factor was named based on the items with higher load values. The first factor was called "Personal values"; the second, "Family life"; the third, "Bohemian"; the fourth, "Socially aware"; and the fifth, "Modern". Last, the factor scores were generated. After carrying out a factor analysis for the maternal nonbehavioral lifestyle questionnaire, categorization of mothers into domains generated by cluster analysis was performed. The scores of the five domains generated in the factor analysis were the statistical variable used for this analysis. The hierarchical algorithm chosen for this questionnaire was Ward's method, with squared Euclidean as similarity measure. After forming the cluster, a dendrogram was built. With it, we chose to maintain three groups. The group was named "Cluster of non-behavioral life- 
style". The first group was named "Socially aware" and comprised mothers with high scores in the domains "family life" and "socially aware"; the second group was defined as "Self-actualization" 45 and comprised mothers with high scores in the domain "personal values"; while the group defined as "Consumerist" comprised mothers with high scores in the domain "modern".

\section{Factor and cluster analysis in the food frequency questionnaire for preschoolers}

Factor analysis was performed with extraction of main components from the food frequency questionnaire. The Bartlett's sphericity test produced a p-value $<0.001$ and the Kaiser Mayer Olkin test a value of 0.72 , indicating that the correlation matrix was suitable for factor analysis. The latter generated three factors with eigenvalues greater than 2.0. With a scree plot, three factors previous to the inflection point of the curve were identified, and then retained and rotated. The three factors retained explained $26 \%$ of the total variance. Due to issues concerning the nomenclature used in studies on food, the factors generated from the food frequency questionnaire were called "patterns". The patterns were appointed based on foods with higher load values, using the classification of foods suggested in the Food Guide for the Brazilian population. ${ }^{46}$ Thus, pattern 1 was defined as "Healthy", pattern 2 as "Junk food", and pattern 3 as "Mixed", since it contained both healthy and junk food. After carrying out a factor analysis through extraction of main components from the food frequency questionnaire, the children were divided into the different patterns generated by cluster analysis. The scores of each pattern generated in the factor analysis were the statistical variable used for this analysis. The hierarchical algorithm chosen for this questionnaire was the method of complete linkage, with squared Euclidean as similarity measure. After forming the cluster, a dendrogram was built. With it, we chose to maintain two groups. The group was named "Food cluster". The first group was defined as "Minimally processed" as it comprised children with high scores in the domain of "minimally processed" foods, while the second group was defined as "Ultra-processed" comprising children with high scores in the domains of "ultra-processed" foods and "mixed".

\section{Other analyses}

The categorical variables were described according to their frequencies in percentages and intervals with $95 \%$ confidence. Association with the outcome was performed using chi-square test. The continuous variables were de- scribed as means and standard deviations; then they were categorized for the association with the outcome using chi-square test according to the cutoff points previously cited for each variable. For ordinal categorical variables, the existence of a trend was verified using chi-square test for trend. For the difference of mean age of mothers among the categories of cluster and behavior lifestyle classes, we used variance analysis.

The odds ratio (OR) was calculated by logistic regression to quantify the gross and adjusted association between the outcome and the independent variables. The covariates were selected with the aid of a direct acyclic graph (DAG). ${ }^{47}$ For the adjusted association between maternal covariates and nutritional characteristics of the preschool child, each was ordered according to their specific temporal relationship: gender, maternal education, maternal age, marital status, region of residence, economic class, depressive symptoms, type of school, and the child's age. The relationship of understanding between variables is facilitated by the identification of the temporal order. With that, we build paths based on temporality and theoretical assumptions. The model resulting from the associations was built using a DAGitty browser ${ }^{47}$ and the minimal sufficient adjustment to estimate the total effect of maternal exposures on the nutritional characteristics of the preschoolers included: economic class, maternal education, marital status, age of child, maternal age, and depressive symptoms.

We have set the probability of rejecting the null hypothesis at $5 \%$. Stata software package version 12.0 was used.

\section{Results}

A total of 255 mother-child dyads participated in the study. The mothers were on average 32 years old (SD 6.2 years), and belonged to all economic classes $[A=8.6 \%(95 \mathrm{CI}$ 5.1-12.1); $\mathrm{B}=39.2 \%$ (33.1-45.2); $\mathrm{C}=47.1 \%$ (40.9-53.2); and $\mathrm{D} / \mathrm{E}=5.1 \%$ (2.3-7.8)]; they lived in all subdistricts studied [Butantã 13.7\% (9.5-17.9); Morumbi 15.7\% (11.2-20.2); Raposo Tavares 25.5\% (20.1-30.9); Rio Pequeno 29\% (23.434.6); and Vila Sônia 16.1\% (11.5-20.6)], presented all levels of education [illiterate $1.6 \%$ (0.03-3.1); complete primary school 12.2\% (8.1-16.2); complete middle school 23.9\% (18.6-29.2); complete high school 44.7\% (38.6-50.8); university graduates $17.6 \%$ (12.9-22.4)], all marital statuses [single $22.7 \%$ (17.5-27.9); married 66.3\% (60.4-72.1); divorced 3.9\% (1.5-6.3); separated 6.3\% (3.2-9.2); and widowed $0.8 \%(-0.3-1.8)]$, and belonged to all categories of non-behavioral lifestyle clusters [socially aware $44.7 \%$ (38.6-50.8); self-actualization $17.3 \%$ (12.6-21.9); or con- 
sumerist 38\% (32-44)], and all categories of behavioral lifestyle, except "needs improvement" [excellent 8.2\% (4.811.6); very good $51.8 \%$ (45.6-57.9); good 33.3\% (27.5-39.2); regular 6.7\% (3.6-9.7)]. They fit most often in economic class C (average income of BRL 962.00 to BRL 1459.00), living in the subdistrict of Rio Pequeno, with high school education, married, presenting non-behavioral socially aware lifestyle and behavioral lifestyle considered "very good". The children's mean age and time spent in front of the television were 5 years (SD 0.7 years) and 132 (SD 82.3 minutes) minutes, respectively. They were mostly female [54.1\% (47.9-60.3)], enrolled in public schools [79.6\% (74.6-84.6)], with normal weight [39.6\% (33.5-45.6)] according to $z$-score for BMI/age, without central adiposity measured by waist circumference [66.3\% (60.4-72.1)], with sedentary behavior [65.1\% (59.2-70.9)], and minimally processed food intake [58.8\% (52.7-64.9)]. As for the nutritional status of the children, $35.3 \%$ were at risk for overweight, and $23.9 \%$ were overweight or obese.

Table 1 shows the sociodemographic characteristics of mothers and preschool children per cluster of non-behavioral lifestyle and type of behavioral lifestyle. In the characterization of the main clusters, the socially aware mothers were older and had higher socioeconomic status, while the consumerist mothers were younger and had lower socioeconomic status. With regard to the type of behavioral lifestyle, the mothers with health behaviors considered "regular" had less education and were single, while the mothers with health behaviors ranked as "good" to "excellent" had completed high school and were married.

Table 2 shows the nutritional characteristics of preschool children by cluster of maternal non-behavioral lifestyle and types of maternal behavioral lifestyle. The food cluster was associated with the cluster of maternal non-behavioral lifestyle with statistical significance. The children who ate minimally processed food were born from mothers with a more socially aware non-behavioral lifestyle, while the children who ate more processed food were born from mothers with a more consumerist non-behavioral lifestyle. No association was found between nutritional characteristics of preschoolers and types of maternal behavioral lifestyle.

Table 3 shows the analysis of univariate and multivariate logistic regression between child outcomes by cluster categories and scoring categories of maternal non-behavioral lifestyle domains and maternal behavioral lifestyle. As for the univariate analysis, the children who did not present "normal weight" had a 74\% higher chance of having mothers with high scores for the non-behavioral lifestyle domain "personal values", compared to the moth- ers with "low to moderate" scores. The children with "sedentary behavior" had $81 \%$ more chances of being born to mothers from the "consumerist" non-behavioral lifestyle cluster compared with the mothers from the "socially aware" cluster. The children who ate "ultra-processed" foods had $121 \%$ more chances of being born to mothers from the "consumerist" non-behavioral lifestyle cluster compared with the mothers from the "socially aware" cluster. The children who ate "ultra-processed" foods had $44 \%$ less chances of being born to mothers with "high" scores in the domain of non-behavioral lifestyle "family life" compared with the mothers with "low to moderate" scores. In the multivariate analysis, the children who did not present "normal weight" and those with central adiposity had 99 and $92 \%$ more chances, respectively, of being born to mothers with "high" scores in the non-behavioral lifestyle domain "modern" compared to the mothers that had "low to moderate" scores. The children with "sedentary behavior" and who ate "ultra-processed" foods had 113 and 84\% more chances, respectively, of being born to mothers from the "consumerist" non-behavioral lifestyle cluster compared with the mothers from the "socially aware" cluster.

\section{Discussion}

In our study, we found the association between categories of maternal non-behavioral and behavioral lifestyle and the sociodemographic characteristics of both mothers and preschoolers. In the characterization of the main clusters, the socially aware mothers were older and had higher socioeconomic status, while the consumerist mothers were younger and had lower socioeconomic status. With regard to behavioral lifestyle, the mothers with health behaviors considered "regular" had less education and were single, while the mothers with health behaviors ranked as "good" to "excellent" had completed high school and were married. In addition, we found the association between categories of maternal non-behavioral and behavioral lifestyle and the nutritional characteristics of the preschoolers. We were able to identify that the maternal non-behavioral lifestyle is associated with the nutrition of preschool children, but not with their nutritional status, presence of central adiposity or sedentary behavior; we also found that mothers with a socially aware lifestyle had children with better nutrition, while the mothers presenting lifestyle defined as "consumerist" had children with worst nutrition. There were no associations between maternal behavioral lifestyle and the nutritional characteristics of these preschool children. After the removal of the effect that confounding variables could have on the 


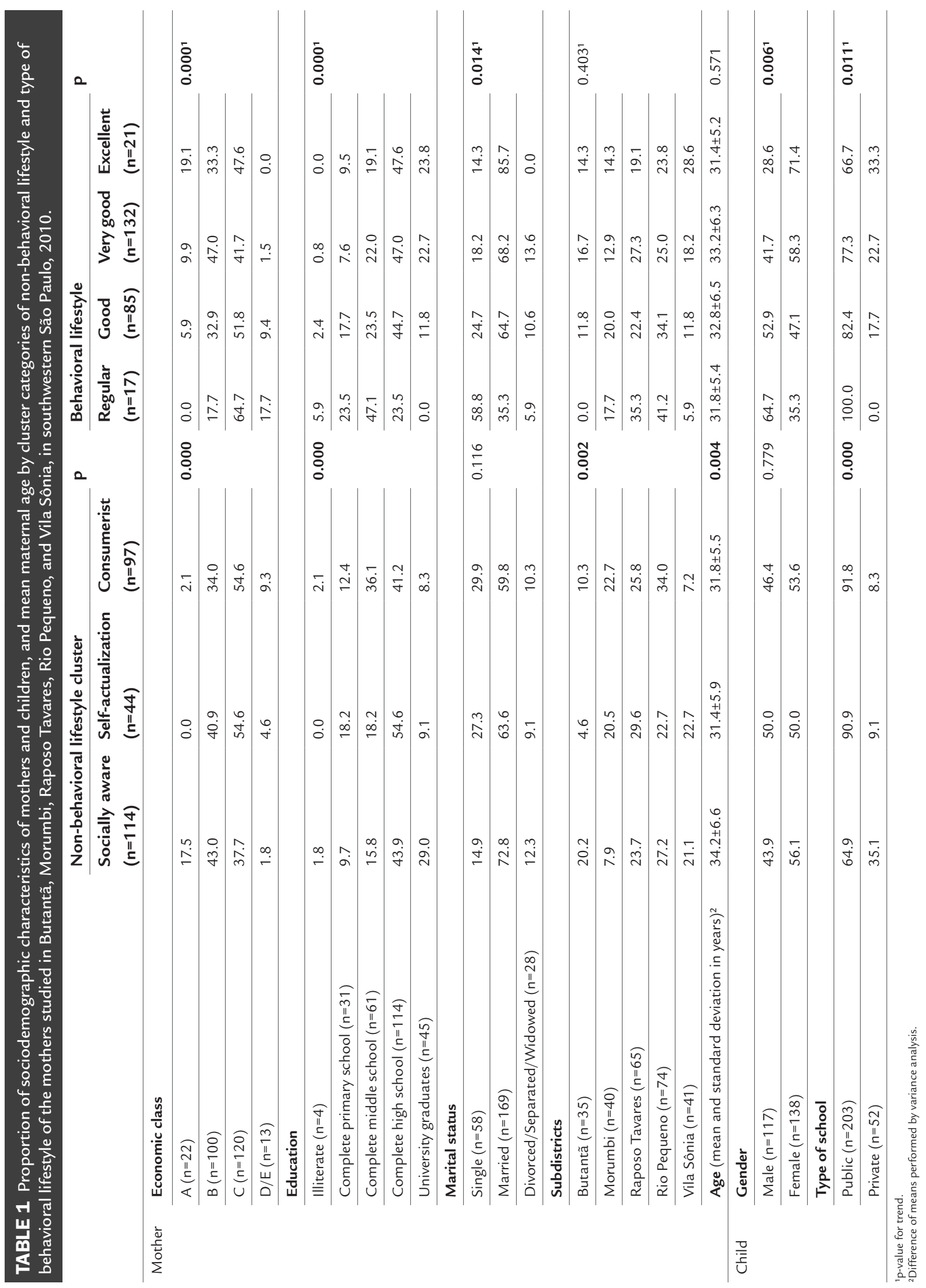




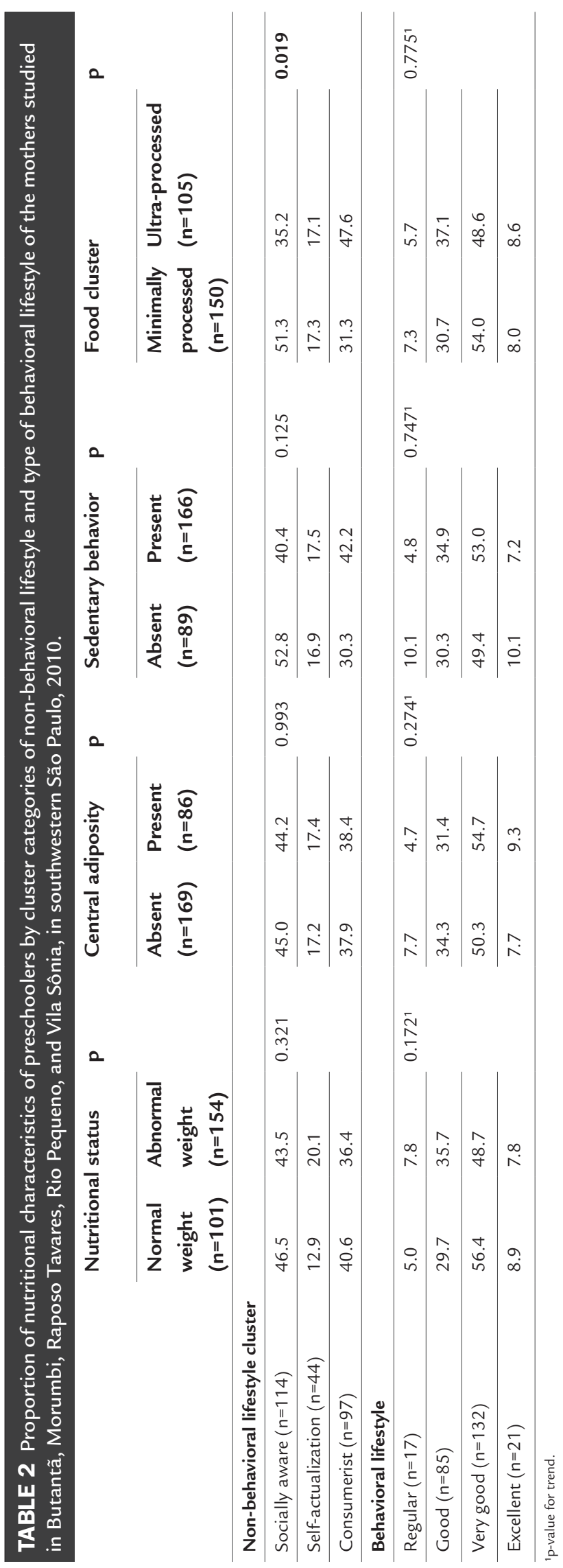




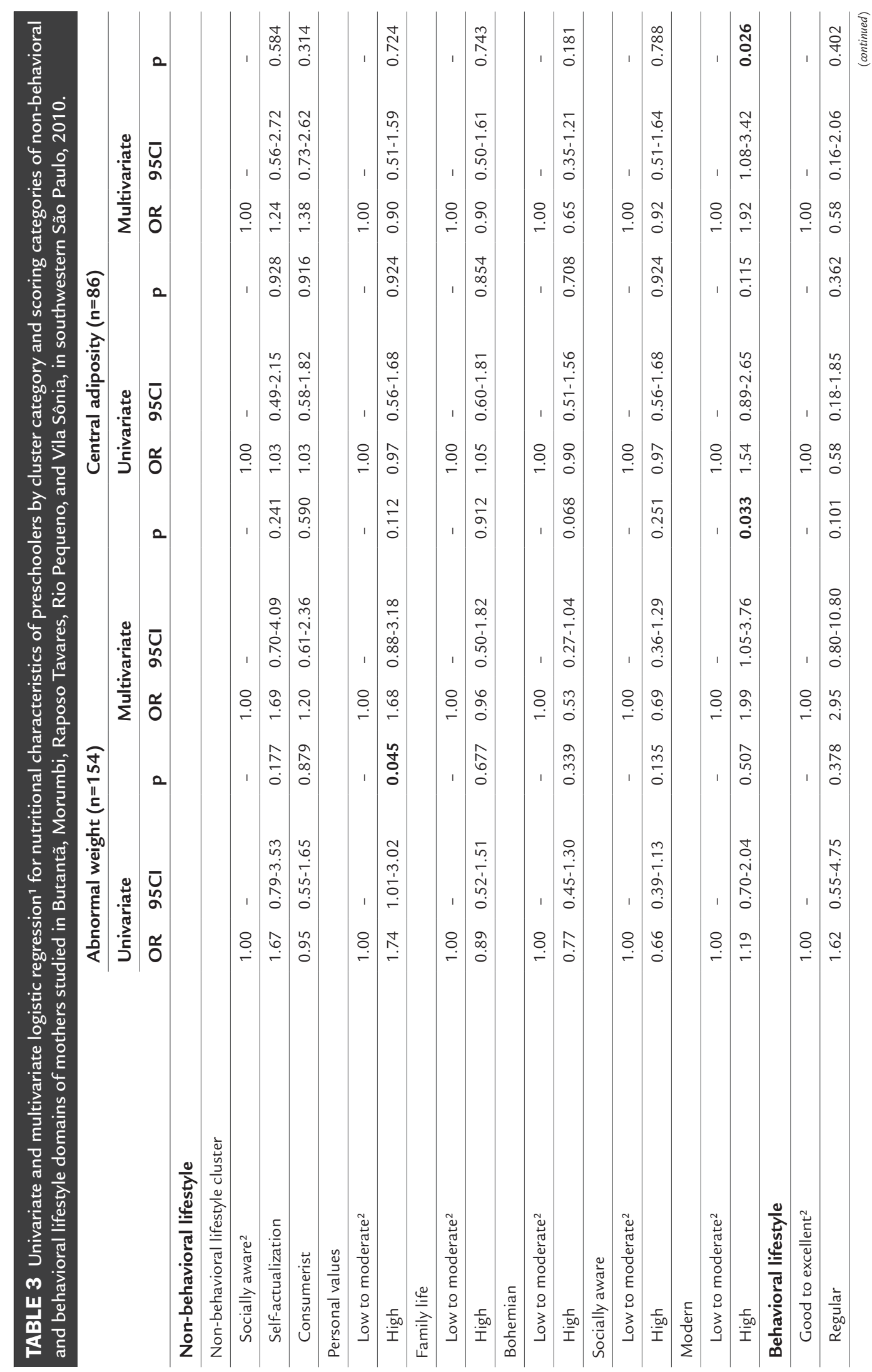




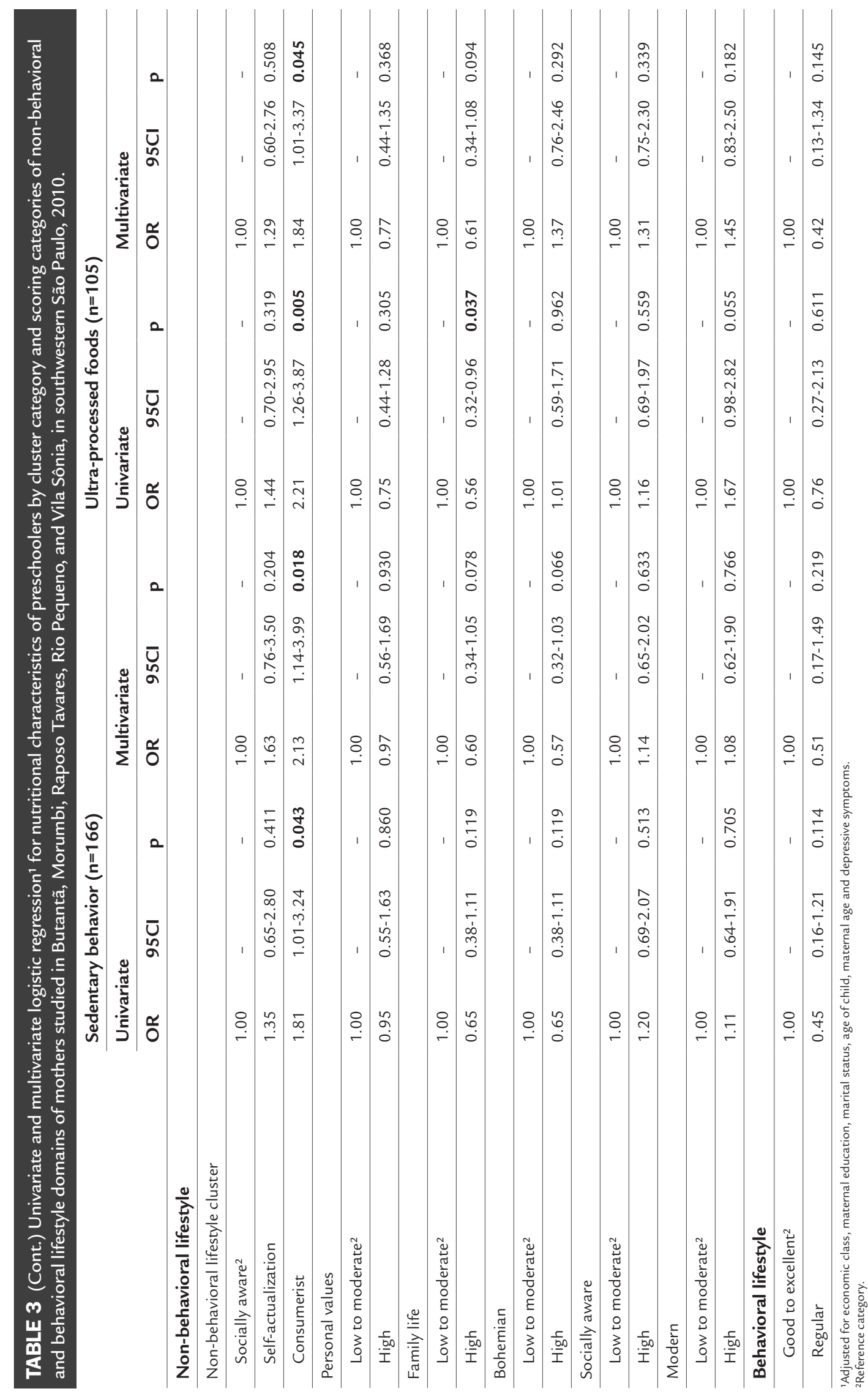


association found, the chances of the children having worst nutritional characteristics were significantly higher for both the "consumerist" cluster and the "modern" behavioral lifestyle domain.

Analyzing the associations found, we can understand that the activities, interests, opinions, and values of mothers belonging to the "socially aware" cluster are in favor of the care and education of the children. In this case, we understand that the time spent by the mothers in the socially aware cluster is in line with their interests and activities benefiting the family, their children and friends, probably leading them to spare time to prepare at home food that is included in the "minimally processed" cluster, as well as spending less money on ultra-processed food items.

Conversely, regarding the mothers belonging to the "consumerist" non-behavioral lifestyle cluster, we can understand that the activities, interests, opinions, and values move in the opposite direction of childcare. It is understandable that mothers with higher adherence to fashion, clothing etc. may have additional financial costs to those necessary for the nutritional care of children. Additionally, we can infer that the time of consumerist mothers is affected by their fashion interests and activities as well as other interests and activities, with little or no time for food preparation at home or for recreational activities with their children. Thus, we observe that children who do not present normal weight, have central adiposity, consume ultra-processed food items and are sedentary have a high chance of being born to others with consumerist lifestyle characteristics. Although this was not the purpose of our research, we found that mothers with lower socioeconomic status fed their children with more ultra-processed food. It is noteworthy that the consumerist mothers belonged to economic class $\mathrm{C}$.

In some investigations with children in preschool age, the association between the mothers' food practices, the food behavior of the children and the consequences on the nutritional status of the latter was demonstrated. ${ }^{48-50}$ The influence of the mother-child relationship on the child's food behavior occurs through interactions with several aspects of daily life, such as lack of time to cook, cultural, social and family interference, and the mother's personal history regarding food habits. Many mothers may adopt criteria unrelated to health when choosing food: price, ease of preparation, taste, appearance, advertising, packaging, the manner how items are placed on the shelves etc. Several psychosocial factors, rather than the physiological needs, including social influences, beliefs and the type of lifestyle, contribute to promote unhealthy food choices. Thus, the relationship between maternal behavior and health can be grounded in the beliefs, personal values, interests and attitudes in life, with their implications for the formation of the children's health behaviors. ${ }^{51}$

In the healthcare area, studies use measuring instruments for disease risk factors. In this context, we did not find any studies assessing maternal lifestyle and its association with the nutrition of preschoolers in view of activities, interests, opinions, and values inherent to the mothers' way of life. Comparisons with other studies are therefore limited.

Four biases could be identified in this research. The first is a selection bias in which, at the time of study design, the inclusion and exclusion criteria were not well established, and we did not verify the occurrence of depression that could lead to difference in non-behavioral lifestyle compared to mothers without depression. This limitation was reduced at the stage of data analysis, with the adjustment for the confounding variable "depressive symptoms" based on the domain "insight" of the FANTASTIC behavioral lifestyle questionnaire. Still as to selection bias, the informative notes left in the child's diary did not reach their goal among illiterate mothers. In addition, mothers who agreed to participate could have a different lifestyle compared to those who refused to participate, which is a fact that cannot be known. The presence of other chronic diseases in children was not verified either. The second bias is one of measurement, in which mothers and children were weighed with minimal clothing. The third is a memory bias, in which mothers had to remember their children's food consumption frequency, how much time the children spent watching television, and how they behaved before each item of the lifestyle questionnaires. The fourth is the information bias. At the time of interview, we did not collect information on how long the children remained with their mothers, or if they were under the care of another person (grandmother or grandfather, father, brothers, uncles, neighbors etc.).

Despite the aforementioned limitations, this study is the gateway to several others in the context of maternal non-behavioral lifestyle. Ours is a cross-sectional study, but other studies, such as cohort analyses, can check the evolution of maternal lifestyle and the children's health, which can change over the years. Consumerist mothers can become self-actualizated or socially aware and vice versa. Also, new domains and the clusters can be identified. In short, this research opens up a range of possibilities for further research in non-behavioral lifestyle and health, which can be used not only in the mother-child relationship, but also to understand lifestyle as a determinant of health at any stage of life being studied. 
In the study of lifestyle by segments, one or more predominant lifestyles can be found in a group of mothers through cluster analysis. However, it should be noted that no lifestyle found excludes others, since each person may have different exposure levels in each case, which can be proved by factor analysis. Therefore, mothers or any other people may have a particular lifestyle as the main feature, but also present other types with different intensities. As seen in the results, there is an association between non-behavioral lifestyle and socioeconomic class. Our study revealed the consumerist mothers had lower socioeconomic status, while the socially aware mothers had higher socioeconomic status. However, we could not determine whether the economy class led to a certain lifestyle.

The non-behavioral approach to lifestyle is innovative because it is a chance to better understand other maternal characteristics associated with the children's health.

A child's health status can have long-term consequences; for example, the onset of CNCDs in childhood due to poor nutrition, overweight, and the presence of central obesity. Our research provides contributions to epidemiologists, government agencies, companies, and others in order to facilitate the creation of policies to raise awareness of mothers about their way of living and its impact on child health. Consequently, it is possible to collaborate with the reduction of incidence of CNCD from childhood. As suggested by Marmot, scientific research must include the causes of disease causes.

Maternal lifestyle is a social determinant of health, and it has non-behavioral aspects associated with child health. Mothers with consumerist characteristics can adversely impact their children's health, as well as their own. Given that the non-behavioral approach is innovative within the scope of lifestyle, more studies are needed to better understand the association with child outcomes.

\section{Resumo}

Associação do estilo de vida materno com a nutrição de pré-escolares

Introdução: muitos dos comportamentos de saúde envolvidos no aparecimento das doenças crônicas não comunicáveis são originados na infância sob influência dos pais. A mãe é a pessoa mais envolvida na educação e nos cuidados de saúde da criança. O estilo de vida (EdV) é um determinante social da saúde. Poucos estudos compreenderam a influência do EdV materno na nutrição infantil.
Objetivo: verificar a associação do $\mathrm{EdV}$ materno comportamental e não comportamental com aspectos nutricionais do pré-escolar.

Método: entre janeiro e dezembro de 2010, realizou-se um estudo transversal com 255 pares de mães-pré-escolares moradoras de cinco subdistritos da região sudoeste, do município de São Paulo. Selecionou-se uma amostra probabilística aleatória estratificada proporcional, com dois estratos ("escola" e "criança”). Da mãe, foram coletadas informações sociodemográficas e de EdV. Da criança, foram coletadas informações antropométricas, de comportamento sedentário e consumo alimentar. As associações foram calculadas por meio do teste do qui-quadrado e por regressão logística.

Resultados: as crianças com alimentação "minimamente processada" eram filhas de mães com EdV não comportamental mais "socioconsciente", enquanto as crianças com alimentação "ultraprocessada" eram filhas de mães com EdV não comportamental mais do tipo "consumista". Nenhuma associação foi encontrada entre as características nutricionais do pré-escolar e os tipos de EdV materno comportamental. As crianças com "comportamento sedentário presente" e alimentação "ultraprocessada" tiveram chances 113 e $84 \%$ maiores, respectivamente, de serem filhas de mães pertencentes ao cluster "consumista".

Conclusão: mães com EdV do tipo "consumista" podem proporcionar influências negativas na nutrição infantil.

Palavras-chave: relações mãe-filho, estilo de vida, pré-escolar, estado nutricional, atividade motora, nutrição da criança.

\section{References}

1. Nobre EB, Grisi SJFE, Ferraro AA. Mother's lifestyle: development of a questionnaire to access a determinant of children's health. A cross-sectional study. Sao Paulo Med J. 2014; 134(1):3-12.

2. Tremblay L, Rinaldi CM. The prediction of preschool children's weight from family environment factors: gender-linked differences. Eat Behav. 2010; 11(4):266-75

3. Vereecken C, Maes L. Young children's dietary habits and associations with the mothers' nutritional knowledge and attitudes. Appetite. 2010; 54(1):4451.

4. Blissett J. Relationships between parenting style, feeding style and feeding practices and fruit and vegetable consumption in early childhood. Appetite. $2011 ; 57(3): 826-31$

5. Gregory JE, Paxton SJ, Brozovic AM. Maternal feeding practices predict fruit and vegetable consumption in young children. Results of a 12-month longitudinal study. Appetite. 2011; 57(1):167-72.

6. De Coen V, Vansteelandt S, Maes L, Huybrechts I, De Bourdeaudhuij I, Vereecken C. Parental socioeconomic status and soft drink consumption of the child. The mediating proportion of parenting practices. Appetite. 2012; 59(1):76-80.

7. Manions Y, Moschonis G, Grammatikaki E, Anastasiadou A, Liarigkovinos T. Determinants of childhood obesity and association with maternal perceptions of their children's weight status: the "GENESIS" study. J Am Diet Assoc. 2010; 110(10):1527-31. 
8. Chaparro MP, Langellier BA, Kim LP, Whaley SE. Predictors of accurate maternal perception of their preschool child's weight status among hispanic WIC participants. Obesity. 2011; 19(10):2026-30.

9. Giacomossi MC, Zanella T, Höfelmann DA. Percepção materna do estado nutricional de crianças de creches de cidades do sul do Brasil. Rev Nutr. 2011; 24(5):689-702.

10. Lara-Garcia B, Flores-Peña Y, Alatorre-Esquivel MA, Sosa-Briones R, CerdaFlores RM. Percepción materna de sobrepeso-obesidad infantil y riesgos de salud en Nuevo Laredo, Tamaulipas, México. Salud Publica Méx. 2011; 53(3):258-63.

11. Chen S, Binns CW, Maycock B, Zhao Y, Liu, Y. Chinese mothers' perceptions of their child's weight and obesity status. Asia Pac J Clin Nutr. 2014; 23(3):452-8.

12. Kim HO, Kim GN, Park E. Perception of childhood obesity in mothers of preschool children. Osong Public Health Res Perspect. 2015; 6(2):121-5.

13. Viner RM, Cole TJ. Television viewing in early childhood predicts adult body mass index. J Pediatr. 2005; 147(4):429-35.

14. Blissett J, Haycraft E, Farrow C. Inducing preschool children's emotional eating: relations with parental feeding practices. Am J Clin Nutr. 2010; 92(2):359-65.

15. Fisher JO, Wright G, Herman AN, Malhotra K, Serrano EL, Foster GD, et al. "Snacks are not food". Low-income, urban mothers' perceptions of feeding snacks to their preschool-aged children. Appetite. 2015; 84:61-7.

16. Lewis M, Worobey J. Mothers and toddlers lunch together. The relation between observed and reported behavior. Appetite. 2011; 56(3): 732-6.

17. Lumeng JC, Ozbeki TN, Appugliese DP, Kaciroti N, Corwyn RF, Bradley $\mathrm{RH}$. Observed assertive and intrusive maternal feeding behaviors increase child adiposity. Am J Clin Nutr. 2012; 95(3):640-7.

18. Morrison H, Power TG, Nicklas T, Hughes SO. Exploring the effects of maternal eating patterns on maternal feeding and child eating. Appetite. 2013; 63:77-83.

19. Hesketh KR, Goodfellow L, Ekelund U, McMinn AM, Godfrey KM, Inskip $\mathrm{HM}$, et al. Activity levels in mother and their preschool children. Pediatrics. 2014; 133(4):973-80.

20. Speirs KE, Liechty JM, Wu CF; Strong Kids Research Team. Sleep, but not other daily routines, mediates the association between maternal employment and BMI for preschool children. Sleep Med. 2014; 15(12):1590-3.

21. Walsh AD, Lioret S, Cameron AJ, Hesketh KD, McNaughton SA, Crawford $\mathrm{D}$, et al. The effect of an early childhood obesity intervention on father's obesity risk behaviors: the Melbourne InFANT Program. Int J Behav Nutr Phys Act. 2014; 11:18.

22. Park SH, Kim MJ, Park CG, McCreary L, Patil C, Norr KF. Family factors and body mass index among Korean-American preschoolers. J Pediatr Nurs. 2015; 30(6):101-11.

23. Stifter CA, Moding KJ. Understanding and measuring parent use of food to soothe infant and toddler distress: a longitudinal study from 6 to 18 months of age. Appetite. 2015; 188-96.

24. Wen LM, Baur LA, Simpson JM, Xu H, Hayes AJ, Hardy LL, et al. Sustainability of effects of an early childhood obesity prevention trial over time: a further 3-year follow-up of the healthy beginnings trial. JAMA Pediatr. 2015; 169(6):543-51.

25. Zhou N, Cheah CSL, Van Hook J, Thompson DA, Jones SS. A cultural understanding of Chinese immigrant mothers' feeding practices. A qualitative study. Appetite. 2015; 87:160-7.

26. Anderson SE, Whitaker RC. Attachment security and obesity in US preschoolaged children. Arch Pediatr Adolesc Med. 2011; 165(3):235-42.

27. Gemmill AW, Worotniuk T, Holt CJ, Skouteris H, Milgrom J. Maternal psychological factors and controlled child feeding practices in relation to child body mass index. Child Obes. 2013; 9(4):326-37.

28. Braungart-Rieker JM, Moore ES, Planalp EM, Lefever JB. Psychosocial pathways to childhood obesity: a pilot study involving a high risk preschool sample. Eat Behav. 2014; 15(4):528-31.

29. Morrissey TW, Dagher RK. A longitudinal analysis of maternal depressive symptoms and children's food consumption and weight outcomes. Public Health Nutr. 2014; 17(12):2759-68.

30. Wendland BE, Atkinson L, Steiner M, Fleming AS, Pencharz P, Moss E, et al. Low maternal sensitivity at 6 months of age predicts higher BMI in 48 month old girls but not boys. Appetite. 2014; 82:97-102
31. Berenson GS, Srinivasan SR, Bao W, Newman III WP, Tracy RE, Wattigney WA. Association between multiple cardiovascular risk factors and atherosclerosis in children and young adult: the Bogalusa Heart Study. N Engl J Med. 1998; 338(23):1650-6.

32. Davis PH, Dawson JD, Riley WA, Lauer RM. Carotid intimal-medial thickness is related to cardiovascular risk factors measured from childhood through middle age: the Muscatine Study. Circulation. 2001; 104(23):2815-9.

33. Raitakari OT, Juonala M, Kähönen M, Taittonen L, Laitinen T, Mäki-Torkko $\mathrm{N}$, et al. Cardiovascular risk factors in childhood and carotid artery intimamedia thickness in adulthood: the Cardiovascular Risk in Young Finns Study. JAMA. 2003; 290(17):2277-83.

34. Magnussen CG, Raitakari OT, Thomson R, Juonala M, Patel DA, Viikari JSA, et al. Utility of currently recommended pediatric dyslipidemia classifications in predicting dyslipidemia in adulthood: evidence from the Childhood Determinants of Adult Health (CDAH) study, Cardiovascular Risk in Young Finns Study, and Bogalusa Heart Study. Circulation. 2008; 117(1):32-42.

35. Hair JF, Black WC, Babin BJ, Anderson RE, Tathan RL. Análise multivariada de dados. 6.ed. Porto Alegre: Bookman, 2009

36. Associação Brasileira de Empresas de Pesquisa. Critério de classificação econômica Brasil. ABEP; 2009.

37. Rodriguez-Añez CR, Reis RS, Petroski EL. [Brazilian version of a lifestyle questionnaire: translation and validation for young adults]. Arq Bras Cardiol. 2008; 91(2):92-8

38. Wilson DMC, Nielsen E, Ciliska D. Lifestyle Assessment: testing the FANTASTIC instrument. Can Fam Physican. 1984; 30:1863-6.

39. Brasil. Ministério da Saúde. Secretaria de Atenção à Saúde. Departamento de Atenção Básica. Orientações para a coleta e análise de dados antropométricos em serviços de saúde: Norma Técnica do Sistema de Vigilância Alimentar e Nutricional - SISVAN. Brasília: Ministério da Saúde; 2011.76 p.

40. Taylor RW, Jones IE, Williams SM, Goulding A. Evaluation of waist circumference, waist-to-hip ratio, and the conicity index as screening tools for high trunk fat mass, as measured by dual-energy X-ray absorptiometry, in children aged 3-19 y. Am J Clin Nutr. 2000; 72(2):490-5.

41. World Health Organization. WHO Anthro software version 3.2.2. Geneva: WHO; 2011

42. World Health Organization. WHO AnthroPlus software for assessing growth of the world's children and adolescents. Geneva: WHO; 2009.

43. American Academy of Pediatrics. Committee on Public Education. American Academy of Pediatrics: children, adolescents and television. Pediatrics. 2001; 107(2):423-6.

44. Colucci ACA, Philippi ST, Slater B. Questionário de frequência alimentar para avaliação do consumo alimentar de crianças de 2 a 5 anos de idade. Rev Bras Epidemiol. 2004; 7(4):393-401.

45. Formiga NS, Gouveia VV. Valores humanos e condutas anti-sociais e delitivas Psicologia: Teoria e Prática. 2005; 7(2):134-70.

46. Brasil. Ministério da Saúde. Secretaria de Atenção à Saúde. Departamento de Atenção Básica. Guia alimentar para a população brasileira. 2.ed. Brasília: Ministério da Saúde; 2014.

47. Textor J, Hardt J, Knüppel S. DAGitty: a graphical tool for analyzing causal diagrams. Epidemiology. 2011; 5(22):745.

48. Fisk CM, Crozier SR, Inskip HM, Godfrey KM, Cooper C, Robinson SM; Southampton Women's Survey Study Group. Influences on the quality of young children's diets: the importance of maternal food choices. Br J Nutr. 2011; 105(2):287-96.

49. Inal S, Cabulat N, Bozkurt $\mathrm{G}$. The effects of healthy lifestyle behaviors of mothers on obesity in preschool children. J Pak Med Assoc. 2015; 65(10):1079-84.

50. Ortiz-Félix RE, Flores-Peña Y, Cárdenas-Villareal VM, Moral de la Rubia J, Ruvalcaba Rodríguez MD, Hernandez-Carranco RG. [Maternal predictors of body mass index of pre-school age children]. Arch Latinoam Nutr. 2015; 65(3):158-65

51. Viana V. Psicologia, saúde e nutrição: contributo para o estudo do comportamento alimentar. Aná Psicológica. 2002; 20(4):611-24 